\title{
Perbaikan proses produksi dan ijin edar guna meningkatkan mutu produk unggulan daerah
}

\section{Suprayogi ${ }^{1 *}$, Nimas Mayang Sabrina Sunyoto ${ }^{2}$, Mochammad Syamsul $\mathrm{Hadi}^{3}$, Umi Fadhilah ${ }^{4}$, Muthia El Afwa ${ }^{5}$, Nadya Lulu Nur Aziza ${ }^{6}$, Reni Zulismar $^{7}$, Bernardia Filia Nareswari ${ }^{8}$, Izzati Ardhan Firdausyi ${ }^{9}$}

\footnotetext{
${ }^{1}$ Universitas Brawijaya, Malang, Indonesia, email: suprayogi99@ub.ac.id

${ }^{2}$ Universitas Brawijaya, Malang, Indonesia, email: nimas.sunyoto@ub..ac.id

${ }^{3}$ Universitas Brawijaya, Malang, Indonesia, email: msh@ub.ac.id

${ }^{4}$ Universitas Brawijaya, Malang, Indonesia, email: dhilanisya.11@gmail.com

${ }^{5}$ Universitas Brawijaya, Malang, Indonesia, email: muthiaawfazel@gmail.com

${ }^{6}$ Universitas Brawijaya, Malang, Indonesia, email: nadyaluluna@gmail.com

7Universitas Brawijaya, Malang, Indonesia, email: renizlsmr@gmail.com

${ }^{8}$ Universitas Brawijaya, Malang, Indonesia, email: fbernardia@gmail.com

${ }^{9}$ Universitas Brawijaya, Malang, Indonesia, email: iz.ardhan@gmail.com

*Koresponden penulis
}

\section{Info Artikel}

Diajukan: 12 Nov 2020

Diterima: 10 Mar 2021

Diterbitkan: 31 Mar 2021

Keywords:

competitive products; food

safety; marketing license

Kata Kunci:

produk unggulan; keamanan pangan; ijin edar

Lisensi:

cc-by-sa

\begin{abstract}
KWT "Sri Tanjung" was one of the Women Farmers Groups (KWT) in Sukosari Village, Malang Regency. They produced "Jaselang" drinks (ginger, secang, alang-alang) and corn chips. KWT members produced the products with traditional technology and low quality of food safety and they did not have marketing license. The purpose of this service activities was to provide the education of KWT members in the form of training related with good product handling processes to ensure product safety, especially the Good Manufacturing Practices (GMP) and marketing license of National Food and Drug Agency. The method of implementing this community service were preparation, implementation, monitoring, and evaluation. The results of the activities showed that $100 \%$ of the participants could know the definition, benefits, and objectives of implementing GMP. Besides, after the implementation of the marketing license socialization, 100\% of the participants knew the definitions, requirements, methods, and registered the marketing license. The activities increased the knowledge of KWT members regarding the implementation of GMP and marketing license.
\end{abstract}


definisi, manfaat, dan tujuan penerapan GMP. Di samping itu, setelah dilaksanakannya sosialisasi tentang ljin Edar BPOM, 100\% peserta sosialisasi mengetahui definisi, syarat, serta cara dan alur perijinan ljin Edar di BPOM. Melalui kegiatan ini meningkatkan pengetahuan anggota KWT terkait implementasi GMP dan ljin Edar BPOM.

\section{PENDAHULUAN}

Kelompok Wanita Tani "Sri Tanjung" di Desa Sukosari, Kecamatan Kasembon, Kabupaten Malang mendirikan suatu usaha berupa produk minuman "Jaselang" (jahe, secang, alang-alang) dan keripik jagung. Produkproduk tersebut hanya diproduksi dengan penanganan yang sederhana dimana belum dapat dipastikan keamanan dan mutu dari produk tersebut. Pengolahan dan penanganan produk yang sesuai dengan persyaratan dapat menjamin keamanan produk. Keamanan produk ini dapat ditempuh dengan cara mengurangi kontaminan dan memperhatikan sanitasi \& hygiene dalam setiap langkah pembuatan produk. Hal ini tentunya akan mengurangi kasus keracunan pangan di Indonesia dan menambah aspek keunggulan produk (Rianti et al., 2018). Terjaminnya keamanan produk akan membuat tingkat kepercayaan konsumen meningkat terlebih karena produk "Jaselang" dan kripik buah ini diklaim organik dan tanpa bahan tambahan pangan. Meningkatnya kepercayaan konsumen akan meningkatkan nilai jual produk sehingga produk dapat bersaing di pasar yang lebih luas (Aini et al., 2019).

Permasalahan keamanan dan mutu pangan untuk usaha mikro kecil menengah (UMKM) di Desa Sukosari, Kecamatan Kasembon, Kabupaten Malang sampai saat ini belum dapat teratasi. Permasalahan lain dalam UMKM pada umumnya adalah minimnya SDM dan SDA, kondisi sarana prasarana kerja yang kurang diperhatikan, tata letak ruang dan fasilitas yang belum sesuai dengan urutan proses, peralatan kerja yang masih tradisional, kondisi higiene karyawan, kualitas dan keamanan bahan baku, kondisi sanitasi lingkungan UMKM sehingga sangat sulit untuk memenuhi standar-standar kualitas pangan yang baik secara stabil (Pinandoyo dan Masnar, 2019). Oleh karena itu, perlu menginisiasi program pengabdian ini dengan tujuan untuk memberikan edukasi berupa pelatihan terkait dengan proses penanganan produk yang baik untuk menjamin keamanan pada produk. Penulis ingin memberikan informasi terkait Good Manufacturing Practices (GMP) dan Perijinan BPOM yang berlaku di Indonesia kepada masyarakat Desa Sukosari, Kecamatan Kasembon, Kabupaten Malang untuk menjadikan produk "Jaselang" dan keripik jagung menjadi lebih terstandardisasi. Kedua produk ini juga diharapkan dapat bersaing di pasar yang lebih luas dan menjangkau pasar di seluruh Indonesia. Tidak menutup kemungkinan juga, bahwa pelatihan dan pemaparan materi GMP serta perijinan BPOM ini akan diterapkan pada produk-produk lain yang dikembangkan dari KWT Sri Tanjung ini.

Terdapat beberapa persyaratan yang harus dipenuhi jika seseorang atau sekelompok orang ingin membuka usaha dibidang pangan, terutama yang terkait dengan keamanan pangan. Beberapa persyaratan tersebut diantaranya adalah penerapan Good Manufacturing Practices (GMP). Good 
Manufacturing Practices (GMP) adalah suatu pedoman untuk memproduksi suatu produk pangan agar produk yang dihasilkan memiliki kualitas yang baik dan aman untuk konsumen. Aspek-aspek yang dinilai dalam penerapan GMP diantaranya meliputi bangunan, lokasi pabrik, peralatan pengolahan, higienitas pekerja, produk akhir, bahan-bahan yang digunakan dalam proses produksi, pengendalian proses pengolahan, fasilitas sanitasi, penyimpanan produk, keterangan produk, kemasan, label, laboratorium dan transportasi.

Tujuan penerapan Good Manufacturing Practices (GMP) dalam sebuah industri pangan adalah agar produsen dapat memproduksi suatu produk pangan sesuai dengan syarat-syarat yang telah ditentukan dan aman dari segala bentuk kontaminasi yang membahayakan konsumen (Yulia et al., 2020). Selain itu, penerapan GMP juga menjadi salah satu upaya yang dapat dilakukan untuk mengembangkan industri pangan skala kecil agar produk yang dihasilkan memiliki mutu yang baik, aman untuk konsumen, tersedia secara berkesinambungan, dan memiliki daya saing tinggi secara ekonomis serta sesuai dengan tuntutan konsumen (Wardanu dan Anhar, 2016).

Sebagian besar masyarakat awam di Indonesia bersikap masa bodoh dalam mengonsumsi berbagai macam produk yang ada dipasaran. Terlebih lagi sosialisasi tentang produk bersertifikasi halal dan berBPOM masih sangat kurang (Kartina et al., 2020). Adapun persyaratan lainnya terkait keamanan pangan adalah sertifikasi BPOM. BPOM (Badan Pengawas Obat dan Makanan) adalah badan hukum yang bertanggung jawab terhadap keamanan pangan sebagai salah satu upaya perlindungan konsumen. BPOM memiliki wewenang untuk mendeteksi, mengawasi dan memberikan jaminan berupa sertifikasi ataupun ijin edar terhadap produk-produk makanan (Tampubolon, 2018). Adanya sertifikasi pada produk pangan yang dihasilkan oleh industri skala kecil akan memberikan beberapa manfaat diantaranya adalah menjamin kualitas dari produk, meningkatkan kepercayaan konsumen, kualitas produk diakui sehingga jangkauan pemasaran lebih bebas dan luas, dan memberikan kemudahan dalam pengembangan usaha (Sulistyowati et al., 2017).

\section{METODE PELAKSANAAN}

Metode pelaksanaan pengabdian masyarakat ini yaitu persiapan, pelaksanaan, monitoring dan evaluasi. Tahap persiapan meliputi perizinan dan diskusi. Perizinan dilakukan melalui RT/RW, Desa, Kecamatan. Diskusi dilakukan bersama perangkat desa dan pengurus KWT Sri Tanjung untuk mengetahui permasalahan yang sedang terjadi serta solusi yang mungkin diterapkan untuk mengatasi permasalahan tersebut. Data awal pelaksanaan program didapatkan melalui wawancara secara langsung kepada pengurus KWT Sri Tanjung.

Tahap pelaksanaan meliputi sosialisasi program dan pelatihan. Sosialisasi bertujuan untuk memberikan gambaran umum program yang akan dilaksanakan. Pelatihan meliputi pelatihan good manufacturing program (GMP) dan pelatihan BPOM. Pada pelatihan program, pengurus KWT Sri Tanjung diberikan kuesioner tertulis sebelum dan sesudah pelaksanaan program agar dapat diketahui tingkat keberhasilan program. 
Tahap monitoring dan evaluasi dilaksanakan selama 3 bulan. Tujuan dari monitoring dan evaluasi yaitu untuk menyempurnakan hasil pelaksanaan program. Apabila terdapat kendala selama program maka dapat diperbaiki dalam tahap monitoring dan evaluasi.

\section{HASIL DAN PEMBAHASAN}

\section{Pelatihan GMP}

Pelatihan Good Manufacturing Practices (GMP) dilaksanakan selama 1 hari di Desa Sukosari dengan sasaran ibu-ibu pengurus dan anggota KWT Sri Tanjung. Pelatihan ini bertujuan untuk memberikan gambaran mengenai Good Manufacturing Practices dalam pengembangan industri. Dokumentasi kegiatan pelatihan dapat dilihat pada Gambar 1. Sebelum pelaksanaan pelatihan dimulai, peserta pelatihan diberikan kuesioner awal pelaksanaan program. Kuesioner ini akan menunjukkan tingkat pengetahuan dan pemahaman peserta pelatihan mengenai Good Manufacturing Practices. Setelah pelaksanaan program, peserta juga diberikan kuesioner untuk mengetahui tingkat keberhasilan program.

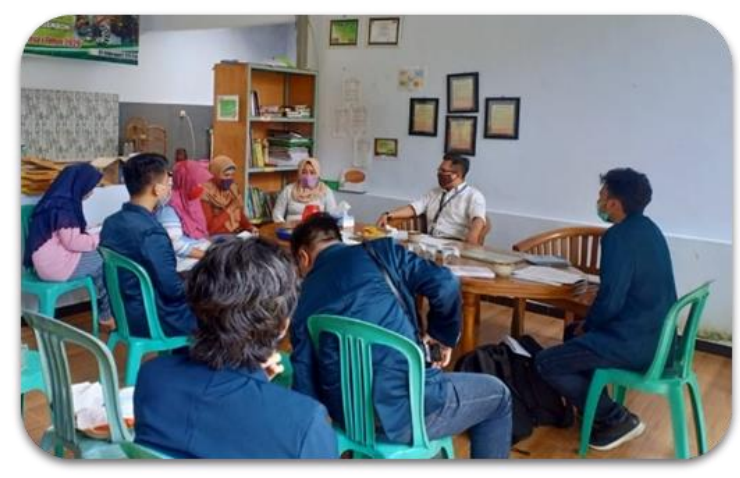

Gambar 1. Pelatihan GMP bersama KWT Sri Tanjung

Good Manufacturing Practices adalah salah satu pengaplikasian kegiatan pengendalian mutu agar menghasilkan produk yang berkualitas dengan melakukan pengendalian yang baik dan teratur (Hermansyah et al., 2013). Good Manufacturing Practices merupakan salah satu persyaratan dasar yang harus dipenuhi pada suatu industri jika ingin menghasilkan produk pangan yang berkualitas dan aman secara konsisten. Persyaratan dalam Good Manufacturing Practices (GMP) mencangkup persyaratan produksi, persyaratan bangunan, lokasi, dan fasilitas serta peralatan produksi dan karyawan. Aspek-aspek yang dinilai dalam penerapapan Good Manufacturing Practices (GMP) diantaranya adalah lokasi pabrik, bangunan, peralatan pengolahan, bahan yang digunakan dalam proses produksi, pengendalian proses pengolahan, personal hygiene, fasilitas sanitasi, label, keterangan produk, 
penyimpanan, produk akhir, pemeliharaan sarana pengolahan dan kegiatan sanitasi, laboratorium, transportasi, dan kemasan.

Kuesioner diberikan kepada peserta pelatihan untuk menunjukkan tingkat keberhasilan program. Kuesioner berisi beberapa pertanyaan yang menjadi parameter keberhasilan pelatihan GMP. Sebelum pelaksanaan program, hanya $40 \%$ masyarakat yang mengetahui apa itu GMP. Setelah pelaksanaan program, $100 \%$ peserta pelatihan dapat mengetahui apa itu GMP. Sebelum pelaksanaan program, belum ada masyarakat yang memahami apa itu GMP. Setelah pelaksanaan program, 100\% peserta pelatihan dapat mengetahui apa itu GMP. Sebelum pelaksanaan program, belum ada masyarakat yang mengetahui bagaimana persiapan penerapan GMP. Setelah pelaksanaan program, 100\% peserta pelatihan dapat mengetahui bagaimana persiapan penerapan GMP. Sebelum pelaksanaan program, belum ada masyarakat yang mengetahui manfaat dan tujuan penerapan GMP. Setelah pelaksanaan program, $100 \%$ peserta pelatihan dapat mengetahui manfaat dan tujuan penerapan GMP. Hasil kuesioner dapat dilihat pada Gambar 2.

\section{Tingkat Pengetahuan Good Manufacturing Practices (GMP)}

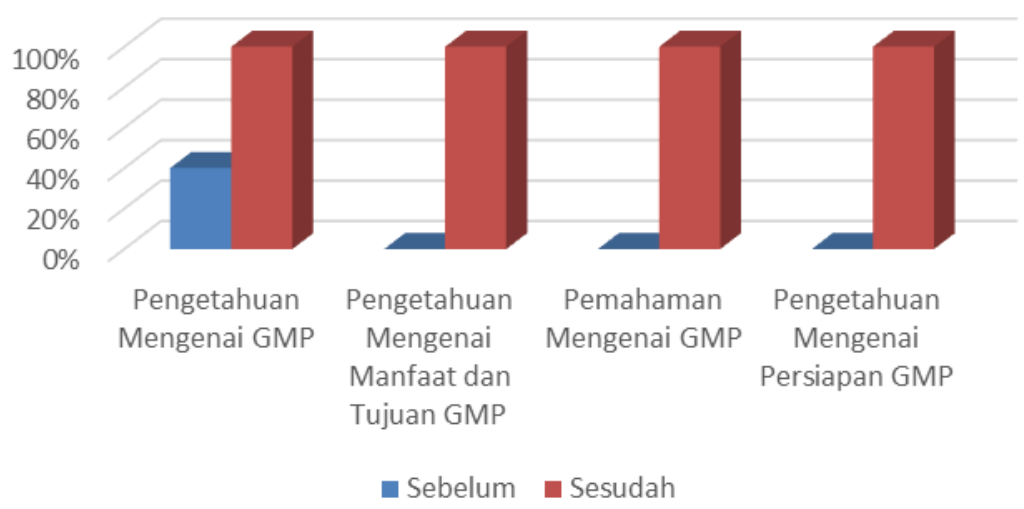

Gambar 2. Tingkat Pengetahuan Good Manufacturing Practices (GMP)

\section{Pelatihan BPOM}

Pelatihan bertemakan BPOM dilaksanakan selama satu hari di Desa Sukosari dengan sasaran ibu-ibu pengurus dan anggota KWT Sri Tanjung. Pelatihan ini bertujuan untuk memberikan gambaran mengenai proses, persyaratan dan alur perizinan produk olahan ke Badan pengawas obat dan makanan. Dokumentasi kegiatan pelatihan dapat dilihat pada Gambar 3. Sebelum pelaksanaan pelatihan dimulai, peserta pelatihan diberikan kuesioner awal pelaksanaan pelatihan dimulai, peserta pelatihan diberikan kuesioner awal pelaksanaan program. Kuesioner tersebut menunjukkan tingkat pemahaman dan pengetahuan peserta pelatihan menganai perizinan BPOM. Setelah pelaksanaan 
program, peserta juga diberikan kuesioner untuk mengetahui tingkat keberhasilan program

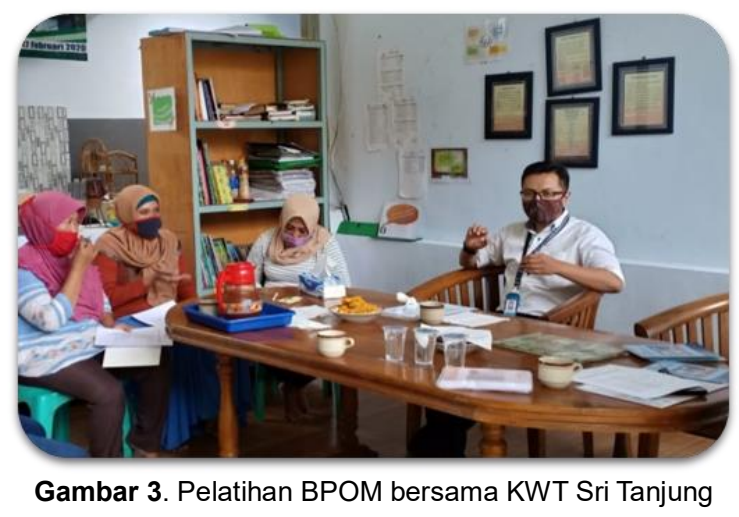

Izin edar BPOM merupakan satu faktor yang penting bagi produk pangan olahan yang akan dipasarkan. Walaupun dalam kenyataannya izin edar lebih berfungsi sebagai nilai tambah suatu produk, namun tidak dipungkiri manfaat dan tujuan dari izin edar ini sangat besar. Izin edar BPOM dalam suatu produk yang dipasarkan menunjukkan jaminan keamanan produk tersebut. Terdapat beberapa syarat yang harus dipenuhi dalam melakukan perizinan BPOM. Persyaratan tersebut meliputi syarat administrasi, teknis pendaftaran pangan olahan, hingga dokumen pendukung (BPOM, 2016). Untuk persyaratan administrasi dibutuhkan dua rangkap yakni satu berupa fotokopi dan satu lainnya berupa dokumen asli.

Kuesioner terdiri dari beberapa pertanyaan yang menjadi parameter keberhasilan pelatihan BPOM. Sebelum pelaksanaan program pelatihan, hanya terdapat $60 \%$ yang mengetahui mengenai apa itu perizinan BPOM. Setelah pelaksanaan program terdapat $100 \%$ peserta pelatihan yang mengetahui hal tersebut. Pengetahuan mengenai syarat perizinan BPOM pada awalnya tidak terdapat peserta yang mengetahuinya, setelah pelatihan program terdapat $100 \%$ peserta yang paham mengenai syarat perizinan BPOM. Tidak terdapat peserta yang mengetahui tentang cara dan alur perizinan BPOM sebelum adanya program pelatihan. Setelah program pelatihan BPOM terdapat 100\% peserta yang paham mengenai cara dan alur perizinan. Hasil kuesioner dapat dilihat pada Gambar 4. 


\section{Tingkat Pengetahuan BPOM}

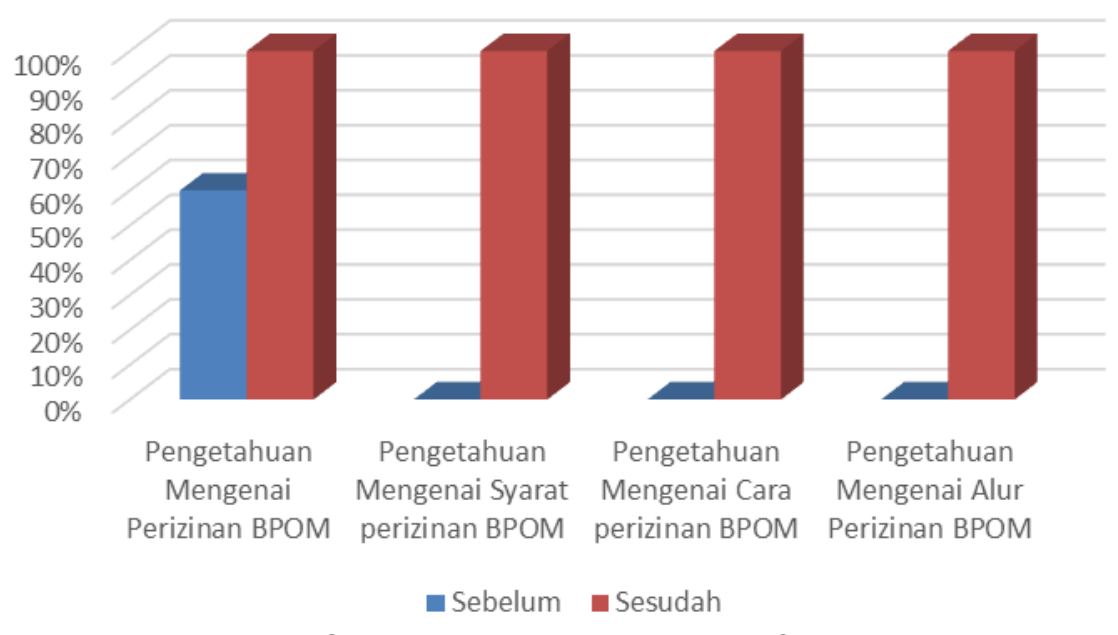

Gambar 4. Tingkat Pengetahuan BPOM

\section{KESIMPULAN}

Melalui program pelatihan mengenai good manufacturing practices (GMP) dan BPOM banyak masyarakat yang belum mengetahui secara jelas tentang hal tersebut. Hanya sebagian kecil masyarakat yang mengetahui tentang dasar-dasar dari GMP dan BPOM. Lebih lanjut secara detail peserta baru memahami melalui program yang telah dilaksanakan. Pengetahuan secara mendalam mengenai manfaat dan tujuan, pemahaman, dan persiapan GMP baru dipahami setelah program. Begitu juga pada pengetahuan mengenai syarat perizinan, cara dan alur perizinan BPOM. Selanjutnya setelah program KWT Sri Tanjung dapat menerapkan GMP sehingga produk olahan yang diproduksi dapat didaftarkan ke BPOM.

\section{UCAPAN TERIMA KASIH}

Penulis mengucapkan terima kasih kepada Lembaga Penelitian dan Pengabdian Masyarakat (LPPM) Universitas Brawijaya melalui kegiatan Doktor Mengabdi (DM) 2020 yang telah membiayai pengabdian masyarakat ini sehingga kegiatan dapat terlaksana dengan baik. Selain itu, penulis juga mengucapkan terima kasih kepada Kelompok Wanita Tani (KWT) "Sri tanjung" di Desa Sukosari Kecamatan Kasembon Kabupaten Malang atas partisipasinya dalam kegiatan pengabdian ini.

\section{DAFTAR RUJUKAN}

Aini, N., Dwiyanti, H., Setyawati, R., Sustriawan, B., \& Alfiyah, S. D. (2019). Sosialisasi dan Pendampingan Pelaksanaan Good Manufacturing Practices (GMP) di UD Annisa, Wonosobo. Aksiologiya: Jurnal Pengabdian Kepada Masyarakat, 3(2), 133-140. https://doi.org/10.30651/aks.v3i2.1699

BPOM. (2016). Pengumuman Peraturan Kepala Badan POM RI Nomor 12 
Tahun 2016 tentang Pendaftaran Pangan Olahan. BPOM RI.

Hermansyah, M., Pratikto, P., Soenoko, R., \& Widha Setyanto, N. (2013). Hazard Analysis and Critical Control Point (Haccp) Produksi Maltosa Dengan Pendekatan Good Manufacturing Practice (Gmp). Journal of Engineering and Management Industial System, 1(1), 14-20. https://doi.org/10.21776/ub.jemis.2013.001.01.3

Kartina;, Nurjanah;; \& Nurmaisah. (2020). Peningkatan pemahaman pelaku umkm dan masyarakat atas produk halal dan aman melalui program pemberdayaan masyarakat di kelurahan juata laut, tarakan-kalimantan utara. Jurnal Pengabdian Masyarakat Borneo, 4(1), 15-22.

Pinandoyo, D. B., \& Masnar, A. (2019). Penerapan GMP pada UKM Keripik SEMAT (Sehat dan Nikmat). Gorontalo Agriculture Technology Journal, 2(2), 51. https://doi.org/10.32662/gatj.v2i2.722

Rianti, A., Christopher, A., Lestari, D., \& Kiyat, W. El. (2018). Penerapan Keamanan dan Sanitasi Pangan Pada Produksi Minuman Sehat Kacang-Kacangan UMKM Jukajo Sukses Mulia di Kabupaten Tangerang. Jurnal Agroteknologi, 12(2), 167-168. https://doi.org/https://doi.org/10.19184/j-agt.v12i02.9283

Sulistyowati, W., Darmadi, B., Rianto, B., \& Sofijanto, M. A. (2017). Sertifikasi Produk Pengolahan Ikan Usaha Kecil dan Menengah. Hang Tuah Press.

Tampubolon, W. S. (2018). Peranan dan Tanggung Jawab Badan Pengawas Obat dan Makanan (BPOM) Terkait Kasus Albothyl Menurut Undang Undang Perlindungan Konsumen. Jurnal IImiah "Advokasi," 6(1), 6978. https://doi.org/10.36987/jiad.v6i1.266

Wardanu, A. P., \& Anhar, M. (2016). Penerapan Good Manufacturing Practice (Gmp) Pada Kelompok Usaha Bersama (Kub) Wida Mantolo Kecamatan Benua Kayong. Jurnal Teknologi Pangan, 7(1), 8-16. https://doi.org/10.35891/tp.v7i1.500

Yulia, A., Yernisa;, Lisani;, Fera, O., \& Rudi;, P. (2020). Pelatihan Good Manufakturing Practice (GMP) bagi UMKM Di Kecamatan Telanaipura. Jurnal Karya Abadi, 4(1), 14-17. https://doi.org/https://doi.org/10.22437/jkam.v4i1.9810 